\title{
RESEÑA
}

\section{La escuela y el lenguaje escrito}

\author{
A propósito del libro de Gloria Rincón Bonilla, publicado por la \\ Escuela de Ciencias del Lenguaje, Univalle, Cali, 1998.
}

\begin{abstract}
Las contribuciones de la lingüística textual, del análisis del discurso, de la sicolinguistica, de la semiótica e, incluso, de la didáctica de la lengua materna, han contribuido a remover los postulados en que se apoyaron las practicas tradicionales de enseñanza de la lectura y la escritura. Gloria Rincón resume en este libro las grandes tesis de esta nueva perspectiva teórica con el fin de señalar los lineamientos mas significativos para refundar las didácticas correspondientes. Los maestros interesados en la construcción de una escuela que forme lectores y productores de textos, encontraran aquí nuevos horizontes para la reconstrucción de sus practicas pedagógicas en este campo de conocimiento.
\end{abstract}

1. Propósito del texto. El texto intenta presentar las principales concepciones sobre el aprendizaje de la lengua escrita, en las cuales se han apoyado diferentes aproximaciones al proceso de enseñanza de la escritura.

La autora afirma que en el ambiente escolar se usan, como sinónimas, las siguientes expresiones: alfabetización, lecto-escritura, enseñanza y aprendizaje de la escritura, desarrollo de habilidades comunicativas para escribir, redacción, composición escrita, o procesos de producción de textos escritos. Según la autora dichos términos no son sinónimos y, además, están asociados a concepciones diferentes.

2. Distinciones fundamentales. En la primera parte comienza planteando un conjunto de distinciones fundamentales. Siendo la primera, la distinción entre escritura y lenguaje escrito.

La escritura es definida como un sistema de notación (letras) y un conjunto de convenciones graficas no alfabéticas (signos de puntuación o de señalización).
$Y$ el lenguaje escrito como formas de discurso usadas y reconocidas por una comunidad especifica, en el ámbito de su vida cotidiana.

Segunda distinción: entre lenguaje oral y lenguaje escrito. Son concebidos como códigos diferentes e incluso como culturas diferentes, relacionadas con modos de pensar y necesidades culturales diferentes.

Pasa luego a definir que entiende por texto: lo fundamental es su carácter semiótico, su grado de unidad, y su estructuración comunicativa y pragmática. Tiene un conjunto de características:

Cohesión: manera como los hablantes de una lengua organizan las unidades de información, para darles unidad conceptual a través de unidades lingüísticas.

Coherencia: relaciones que se establecen entre el tópico de la conversación y el comentario que hace el autor. Para el lector, la comprensión del tópico, orienta la interpretación de todo el texto. Para el autor la claridad sobre el tópico, orienta la organización de todo el texto.

Tercera distinción: entre textos y tipologías textuales. Las formas de organización del lenguaje que un escritor privilegia son los textos o géneros discursivos, y la forma de clasificarlos corresponde a las tipologías textuales.

3. Los textos en el contexto escolar. "En el contexto escolar los textos tienen como propósito fundamental propiciar el aprendizaje de un contenido curricular especifico, por lo cual se reconocen como manifestaciones del discurso pedagógico" (pg.38). 
Los intercambios comunicativos en el ámbito escolar básicamente se efectúan mediante conversaciones. Y es mediante estas conversaciones que ocurren los procesos de enseñanza-aprendizaje.

Hasta hace poco se pensaba que la lectura y la escritura eran solamente un asunto escolar, pero pasaron a ser objetos de estudio y trabajo por parte de lingüistas, sicólogos, sicolinguistas y maestros investigadores.

4. Didáctica dominante sobre la escritura. Debido a la concepción conductista sobre el aprendizaje, los estudios sobre escritura se centraron sobre la relación lenguaje-actividad sensorio motriz. La escritura se concebía como una habilidad viso-motora y se incluía en el ámbito de las habilidades manuales; por lo cual, para estimular su aprendizaje, se trataba de lograr desarrollos a nivel de la motricidad llamada fina y de la coordinación oculo-manual.

En general se creía que el lenguaje escrito era una representación grafica del lenguaje oral. Con base en estas concepciones, la didáctica de la escritura estaba centrada sobre ejercicios de aprestamiento. Sobre el tipo de letra a seleccionar, sobre la exactitud de la copia de un dictado, y sobre la repetición de algo que había dicho el maestro o que había escrito en el tablero.

Aprender a escribir significaba aprender a dibujar letras, aprender a combinar letras, ubicar los signos de puntuación, etc. A medida que el estudiante avanzaba hacia los grados superiores, el proyecto del maestro consistía en multiplicar los ejercicios para "soltar" la mano y automatizar la escritura.

5. Contribución de la Investigación sicolinguistica. Los estudios de Piaget en sicología genética, de Chomsky en la lingüística, y las investigaciones de Emilia Ferreiro y Ana Teberosky pusieron en crisis los postulados de la didáctica tradicional y aportaron elementos para enfocar el asunto desde una nueva óptica, según la cual estos aprendizajes fueron concebidos como procesos complejos de construcción de sentido en los que eran fundamentales los esquemas de pensamiento de lectores y escritores.

Se comenzó a entender que el niño tiene un papel mas activo en el aprendizaje y que ya llegaba a la escuela con algunos conocimientos e hipótesis sobre la escritura. Complementariamente, comenzó a entenderse que el papel del maestro no era tan determinante como parecía, y que debía pasar a ser un facilitador de situaciones de aprendizaje. Su papel paso a un segundo plano, y en algunos casos llego a encubrir su participación. El énfasis paso de la pregunta "¿como enseñar a leer y a escribir?" a la pregunta ¿como aprenden los niños a leer y a escribir?

6. Las contribuciones de Vigotsky. A partir de los desarrollos teóricos de Vigotsky, con su teoría de la mediación de los signos, el aprendizaje comenzó a concebirse como el resultado de un proceso de internalizacion de los instrumentos culturales (signos) a través de la interacción social. Se reconoce entonces la importancia de la mediación semiótica (lingüística) en los procesos de interacción, en la construcción de los procesos sicológicos superiores (pensamiento), y por ende en la construcción del sujeto.

En consecuencia, el aprendizaje escolar comenzó a visualizarse como un proceso de interacción entre maestro y estudiantes, en el cual se co-construyen, revisan y modifican esquemas de conocimiento. Si bien es el alumno el que construye su conocimiento, este proceso ocurre en un ambiente construido por el maestro (intervención pedagógica).

Se comienza también a entender que el lenguaje escrito es un código diferente del lenguaje oral, tanto en su estructura como en su funcionamiento. $Y$ que los diferentes tipos de lenguaje oral, y de lenguaje escrito no se adquieren espontáneamente, sino que son el resultado de enseñanzas especificas y sistemáticas.

7. Didáctica alternativa de la producción escrita. Termina el libro con un conjunto de propuestas pedagógicas que apuntan a la construcción de un ambiente escolar alfabetizador (biblioteca escolar, rincón de lectura, posibilidad de elegir entre varios textos, leer, discutir los contenidos y las interpretaciones, elaborar versiones, etc.). Dada la autonomía del lenguaje escrito con respecto al oral, la producción de textos escritos debe tener en cuenta parámetros como los siguientes: tomar como modelo a los escritores expertos, saber elegir el destinatario o audiencia, elaborar al menos un borrador, trazarse unos objetivos, comenzar a "tejer" la escritura, pensar siempre en el destinatario y no solamente en el tema, etc.

Rafael Avila Penagos Profesor e Investigador UPN 